\title{
Analysis of tennis champions' career: how did top-ranked players perform the previous years?
}

\author{
Javier Maquirriain
}

\begin{abstract}
Professional tennis is a highly competitive sport ranked through an objective, merit-based, mathematical system. The objective of this study was to determine and analyze how top $1^{\circ}$-ranked professional tennis players perform in the previous three years. Data of ranking position of all top $1^{\circ}$-ranked female and male players in the professional era and their performance in Grand Slams tournaments were collected from tennis stakeholders' websites and analyzed.

Top $1^{\circ}$ male players' ranking position averaged $2.17 \pm 1.92$ (Cl 95\%:1.56/2.78), $7.02 \pm 18.073$, and $10.73 \pm 29.31$, at 1 , 2 , and 3 previous years, respectively. Top $1^{\circ}$ female players' ranking position averaged $2.21 \pm 1.59$ (Cl 95\%:1.61/ $2.71), 4.78 \pm 4.09$, and $14.97 \pm 26.75$, at 1,2 , and 3 previous years, respectively. All top $1^{\circ}$ male and female players were ranked within the $1^{\circ}-10^{\circ}$ and $1^{\circ}-6^{\circ}$ positions the previous year, respectively; the majority of tennis champions won at least one Grand Slam tournament during the year before reaching the top $1^{\circ}$ ranking position (females $=69 \%$; males $=65 \%$ ), and during the same season (females $=82 \%$; males $=92 \%$ ). Female and male top $1^{\circ}$-ranked player maintained that position in the following year in $48.7 \%$ and $52.5 \%$ of cases, respectively. In conclusion, tennis players need to perform at high level during at least three years prior to reach the top $1^{\circ}$ position in the professional tennis ranking. Both, male and female champions, showed similar patterns of performance in their professional career.
\end{abstract}

Keywords: Ranking; Sport; Professional

\section{Background}

The majority of professional sports have incorporated statistics to evaluate or forecast matches outcomes. The sport of tennis has lagged behind most its peers in collecting statistics data. However, there is a growing interest in this topic and several studies on tennis rankings and career development have been recently published (Bane et al. 2014; Reid et al. 2014; Reid \& Morris 2011; Brouwers et al. 2012; Radicchi 2011). The career of professional tennis players are measured by the achievement of ranking milestone (Reid et al. 2014). These authors consider that professional tennis rankings provide valuable but underutilized information (Reid et al. 2014).

The International Tennis Federation (ITF), the Women Tennis Association (WTA), and the Association of Tennis Professionals (ATP) are the principal organizing bodies of women and men professional tennis, respectively. The ATP was formed in 1972 by Donald Dell, Jack Kramer,

Correspondence: jmaquirriain@yahoo.com

Argentine Tennis Association, CONICET, Buenos Aires, Argentine and Cliff Drysdale to protect the interests of male professional tennis players. One of the initial acts of the organization was the establishment of a computer ranking system that provided fair analysis of a player's performance as well as an objective means to determine the entries into tournaments. It was created by Jack Kramer, started the following year (23 August, 1973), and has continued through today as the official ranking system in men's professional tennis (Association of Tennis Professional web site, 2014). The WTA was founded in 1973 by Billie Jean King and colleagues. Jerry Diamond is considered the creator the women's point system for ranking players which started in 1975 (Women Tennis Association web site, 2014).

The ITF supervise the four Grand Slam (GS) tournaments, also called "majors", which are the most important annual tennis events and offer the most ranking points and prize money. The Grand Slam itinerary consists of the Australian Open, the French Open (Roland Garros), Wimbledon, and the US Open. 
The objective of this descriptive study was to determine and analyze how top-ranked professional tennis players, male and female, performed the previous three years.

\section{Methods}

The protocol of this observational study was approved by the Ethics Committee of the Nixus Foundation (Permit Number: 2013-07). Informed consent was not required but subjects' ranking positions were de-identified prior to analysis.

Both professional tennis rankings (ATP and WTA) are objective, merit-based, mathematical method of ranking tennis players. These international organizations publish weekly lists, a 52-week rolling computer ranking points based on tournament category. The player with the most points by season's end is the World Number 1 of the year.

Data of ranking position of all top $1^{\circ}$-ranked female and male players in the professional era and their performance in Grand Slams tournaments were collected from tennis stakeholders' websites available in the public domain and analyzed. (Association of Tennis Professional web site, 2014; Women Tennis Association web site, 2014).

Statistical analysis was performed using Statistica ${ }^{\mathrm{TM}}$ software (StatSoft Inc, Tulsa, Oklahoma). Ordinal variables were analyzed through the Mann-Whitney test; t-test was used for other comparisons; $p<0.05$ was considered significant.

\section{Results}

Male circuit

There were 16 different players who reached the top- $1^{\circ}$ position of the ATP ranking at the end of the year during the professional era (1973-2013).

The mean ranking position the year before reaching the top- $1^{\circ}$ place was $2.17 \pm 1.92$ (range $1-10$; CI 95\%: 1.56-2.78; CI 99\%: 1.35-2.99). The first player who reached the top position was not used for analysis because official data regarding his performance during previous years were not available. Data regarding their position in the previous three years are shown in Table 1.

Table 1 Descriptive statistics of top $1^{\circ}$ male players' performance in the ATP year-end ranking

\begin{tabular}{llllll}
\hline Previous year & $\mathbf{n}$ & Average & SD & Range & Cl 95\% \\
\hline 1 & 40 & 2.17 & 1.92 & $1-10$ & $1.56 / 2.78$ \\
2 & 39 & 7.02 & 18.07 & $1-110$ & $1.16 / 12.88$ \\
3 & 38 & 10.73 & 29.31 & $1-156$ & $1.10 / 20.37$ \\
\hline
\end{tabular}

Data included their ranking position at three previous years.
All top $1^{\circ}$ players $(100 \%)$ ranked within the $1^{\circ}-10^{\circ}$ positions the previous year before reaching the peak place. In $52.50 \%$ of cases $(21 / 40)$, the World Number 1 of the year was the same player as the previous season.

Ninety-seven percent of top $1^{\circ}$ players (38/39) were ranked within the $1^{\circ}-25^{\circ}$ positions two years before reaching the peak position. Ninety-four percent of top-1 players $(36 / 38)$ were ranked within the $1^{\circ}-25^{\circ}$ positions three years before reaching the peak position.

The analysis of top $1^{\circ}$ players performance in GS tournaments showed that $65.85 \%(27 / 41)$ had won at least one GS tournament the previous year (fourteen players won one GS tournament; eleven players won two GS tournaments; two players won three GS tournaments). The previous year, top- $1^{\circ}$ players won Wimbledon $(\mathrm{n}=$ $15)$, US Open $(\mathrm{n}=14)$, Roland Garros $(\mathrm{n}=7)$, and Australian Open $(n=6)$. The difference between GS winners and GS non-winners in the previous years was not statistically significant ( $p=0.24$; chi-square test).

Ninety-two percent of top $1^{\circ}$ players $(38 / 41)$ had won at least one GS tournament during the year when they reached that position in the final ranking. Fifteen players won one Grand Slam tournament; fifteen won two Grand Slam tournaments; and seven players won three Grand Slam tournaments. During that season, players won US Open $(n=22)$, Wimbledon $(n=21)$, US Open $(n=22)$, Roland Garros $(n=12)$ and Australian Open $(\mathrm{n}=11)$ Table 2.

There were 16 different male players who reached the top $-1^{\circ}$ ranking position at the end of the calendar year in the professional era. At the year when they reached that position for the first time, all of them (16/ 16) had won at least one Grand Slam tournament (average 1.81). Their performance in Grand Slam tournaments the previous years included are summarized in Table 3.

\section{Female circuit}

There were 11 different players who reached the top $-1^{\circ}$ position of the WTA ranking at the end of the year during the professional era. The mean ranking position the year before reaching the top $-1^{\circ}$ place was $2.21 \pm 1.59$

Table 2 Descriptive statistics of performance in Grand Slam tournaments of male players who reached the $1^{\text {st }}$ position of ATP ranking

\begin{tabular}{lllll}
\hline Season & Winners & $\%$ & GS tournaments & Average \\
\hline Same year & $38 / 41$ & 92.68 & $67 / 38$ & 1.76 \\
$1^{\circ}$ previous year & $27 / 41$ & 65.85 & $42 / 27$ & 1.55 \\
$2^{\circ}$ previous year & $22 / 41$ & 53.65 & $36 / 22$ & 1.63 \\
$3^{\circ}$ previous year & $23 / 41$ & 56.09 & $34 / 23$ & 1.47 \\
\hline
\end{tabular}


Table 3 Descriptive statistics of performance in Grand Slam tournaments of male players who reached the $1^{\text {st }}$ position of ATP ranking for the first time

\begin{tabular}{lllll}
\hline Season & Winners & $\%$ & GS tournaments & Average \\
\hline Same year & $16 / 16$ & 100.00 & $29 / 16$ & 1.81 \\
$1^{\circ}$ previous year & $7 / 16$ & 43.75 & $8 / 16$ & 0.50 \\
$2^{\circ}$ previous year & $4 / 16$ & 25.00 & $4 / 16$ & 0.25 \\
$3^{\circ}$ previous year & $7 / 16$ & 43.75 & $7 / 16$ & 0.43 \\
\hline
\end{tabular}

(range 1-6; CI 95\%: 1.68-2.73; CI 99\%: 1.50-2.91). Again, the first player who reached the top position was not used for analysis because official data regarding her performance during previous years were not available. Data regarding their position in the previous three years are shown in Table 4.

All top- $1^{\circ}$ female players $(100 \%)$ ranked within the $1^{\circ}$ $6^{\circ}$ positions the previous year before reaching the peak place. In $48.71 \%$ of cases (19/39), the World Number 1 of the year was the same player as the previous season.

Ninety-seven percent of top $1^{\circ}$ players $(36 / 37)$ were ranked within the $1^{\circ}-12^{\circ}$ positions two years before reaching the peak position. Eighty-six percent of top $1^{\circ}$ players $(31 / 36)$ were ranked within the $1^{\circ}-22^{\circ}$ positions three years before reaching the peak position.

Sixty-four percent of top- $1^{\circ}$ players $(25 / 39)$ had won at least one GS tournament the previous year (eleven players won one GS tournament; nine players won two GS tournaments; four players won three GS tournaments, and 1 player won four GS). In the previous year, top $1^{\circ}$ players won Wimbledon $(n=13)$, Roland Garros $(\mathrm{n}=13)$, and Australian Open $(\mathrm{n}=10)$, and the US Open $(n=9)$. The difference between GS winners and GS nonwinners in the previous year was not statistically significant ( $p=0.22$; chi-square test).

Eighty-two percent of top $1^{\circ}$ female players (32/39) had won at least one Grand Slam Tournament during the year when they reached that position in the final ranking. Thirteen players won one Grand Slam tournament; eight won two Grand Slam tournaments; ten players won three Grand Slam tournaments; and one player won four Grand Slam tournaments. During that

Table 4 Descriptive statistics of top $1^{\circ}$ female players' performance in the WTA year-end ranking

\begin{tabular}{llllll}
\hline Previous year & $\mathbf{N}$ & Average & SD & Range & Cl 95\% \\
\hline 1 & 38 & 2.21 & 1.59 & $1-6$ & $1.68-2.73$ \\
2 & 37 & 4.78 & 4.09 & $1-16$ & $3.42-6.14$ \\
3 & 36 & 14.97 & 26.75 & $1-95$ & $5.92-24.02$ \\
\hline
\end{tabular}

Data included their ranking position at three previous years.
Table 5 Descriptive statistics of performance in Grand Slam tournaments of female players who reached the $1^{\text {st }}$ position of ATP ranking

\begin{tabular}{lllll}
\hline Season & Winners & $\%$ & GS tournaments & Average \\
\hline Same year & $32 / 39$ & 82.05 & $64 / 32$ & 2.00 \\
$1^{\circ}$ previous year & $27 / 39$ & 69.23 & $47 / 27$ & 1.74 \\
$2^{\circ}$ previous year & $23 / 39$ & 58.97 & $39 / 23$ & 1.69 \\
$3^{\circ}$ previous year & $18 / 39$ & 46.15 & $29 / 18$ & 1.61 \\
\hline
\end{tabular}

season, players won the US Open $(n=19)$, Wimbledon $(\mathrm{n}=17)$, Roland Garros $(\mathrm{n}=15)$, and the Australian Open $(n=12)$. Performance pattern of female tennis champions in GS tournaments are summarized in Table 5.

There were 11 different female players who reached the top $1^{\circ}$ ranking position at the end of the calendar year in the professional era. At the year when they reached that position for the first time in their career, eighty-one percent of them $(9 / 11)$ had won at least one Grand Slam tournament. Their performance in Grand Slam tournaments the previous years included are summarized in Table 6.

\section{Male vs. female comparison}

There were no significant differences between male and female performance pattern at previous years before reaching the top $1^{\circ}$ ranking position. Data are summarized in Table 7 .

\section{Discussion}

Findings of this study indicated that male and female tennis champions need to perform at high level the previous years before reaching the top $1^{\circ}$ position. In the overall professional era (40 consecutive years, 19742013 for men; and 38 consecutive years, 1976-2013 for women) the average of their ranking position the year before reaching the top of the list was " 2 ", with really close data dispersion. Furthermore, all of them (100\%) were ranked within the top- $6^{\circ}$ (females) and the top- $10^{\circ}$ positions (males) the previous year. Confidence intervals

Table 6 Descriptive statistics of performance in Grand Slam tournaments of female players who reached the $1^{\text {st }}$ position of WTA ranking for the first time

\begin{tabular}{lllll}
\hline Season & Winners & $\%$ & GS tournaments & Average \\
\hline Same year & $9 / 11$ & 81.81 & $17 / 9$ & 1.88 \\
$1^{\circ}$ previous year & $2 / 11$ & 18.18 & $3 / 2$ & 1.50 \\
$2^{\circ}$ previous year & $0 / 11$ & 0.00 & $0 / 0$ & 0.00 \\
$3^{\circ}$ previous year & $1 / 11$ & 9.09 & $1 / 1$ & 1.00 \\
\hline
\end{tabular}


Table 7 Gender comparison of players' performance before reaching the top $1^{\circ}$ ranking position

\begin{tabular}{|c|c|c|c|}
\hline & Male & Female & $p$ \\
\hline Previous ranking at 1 year & $2.17 \pm 1.92$ & $2.21 \pm 1.59$ & 0.70 \\
\hline Previous ranking at 2 years & $7.02 \pm 18.07$ & $4.78 \pm 4.09$ & 0.44 \\
\hline Previous ranking at 3 years & $10.73 \pm 29.31$ & $14.97 \pm 26.75$ & 0.83 \\
\hline All top- $1^{\circ}$ ranked at 1 year & $1^{\circ}-10^{\circ}$ & $1^{\circ}-6^{\circ}$ & \\
\hline Same player top $-1^{\circ}$ as past year & $52.50 \%$ & $48.71 \%$ & 0.73 \\
\hline Grand Slam winner the year before & $65.85 \%$ & $69.23 \%$ & 0.86 \\
\hline Grand Slam winner the same year & $92.68 \%$ & $82.05 \%$ & 0.15 \\
\hline Grand Slam winner the same year in \# 1 players for first time & $100.00 \%$ & 81.81 & 0.07 \\
\hline
\end{tabular}

of descriptive statistics (Cummings and Koepsell 2010) showed that there is $95 \%$ of chance that the next top $1^{\circ}$ World player (male and female) will be one player ranked $1^{\circ}, 2^{\circ}$, or $3^{\circ}$ at the present year.

Two years before reaching the top- $1^{\circ}$ ranking position, male players averaged the $7^{\circ}$ place in the ATP year-end ranking, and female players averaged $5^{\circ}$ in the WTA ranking system. The vast majority (94\%) of male players was ranked within the $25^{\circ}$ position at that time, and there was $95 \%$ of chance that the top $1^{\circ}$ player in two years will be ranked within the $1-13^{\circ}$ positions at the present season. In the female circuit, $97 \%$ of players were ranked within the $12^{\circ}$ position two years before reaching the top position, and there is $95 \%$ of possibility that the top $1^{\circ}$ player in two years will be ranked within $3^{\circ}-6^{\circ}$ positions at the present year.

Three years before climbing to the top $-1^{\circ}$ ranking position, players average the $11^{\circ}$ place in the ATP yearend ranking. Most of them (94\%) were ranked within the $25^{\circ}$ position at that time. Moreover, there is a $95 \%$ of chance that the top $1^{\circ}$ player in three years will be ranked within $1^{\circ}-20^{\circ}$ positions at the present season.

The four GS tournaments offer the most ranking points in the professional tennis circuit; therefore, they have a clear influence in the final ranking constitution every year. Undoubtedly, winning a major is considered a cornerstone in the tennis player's career. The majority of tennis champions won at least one GS tournament during the year before reaching the top $1^{\circ}$ ranking position (females $=69 \%$; males $=65 \%$ ), and during the same season (females $=82 \%$; males $=92 \%$ ). Moreover, in the male circuit it seems necessary to win two majors in the same season to become top $1^{\circ}$ for the first time.

High level of performance consistency of top $10^{\circ}$-ranked players has been previously reported (Maquirriain and Cerúndolo 2005; Rohm et al. 2004). It seems to be extremely necessary to perform at very high level during at least three years prior to become top $1^{\circ}$ in male professional ranking. Potential explanation for this issue may be the high competitiveness of the professional circuit, the seeding procedure for drawing the tournaments' matches, and the intrinsic rolling computer system of the ranking, which maintains points during 52 weeks.

Both male and female professional tennis champions showed similar pattern regarding ranking evolution and other performance data. Top $1^{\circ}$ players did not show gender differences in their ranking position in the previous years and overall Grand Slam tournaments. The main difference was found in the rate of majors' winners during the season in which the player reached the top position for the first time. All male champions won a GS tournament that year, whereas some female players (18\%) were able to become a new top $1^{\circ}$ without winning a major event.

Limitations of the current study include its descriptive and retrospective design. Further researches are needed to really predict future positions in tennis rankings.

\section{Conclusions}

According to the findings of this study, it seems to be extremely necessary to perform at very high level during at least three years prior to become top $1^{\circ}$ ranked player in female and male professional tennis circuits. There is $95 \%$ probability that the next top $1^{\circ}$ ranked player will be one ranked within the $1^{\circ}-3^{\circ}$ positions at the present year, and the top $1^{\circ}$ ranked player has approximately $50 \%$ of chances to maintain that position the next year. The majority of tennis champions won a Grand Slam tournament during the year before reaching the top $1^{\circ}$ ranking position and during the same season. Both, male and female tennis players, showed similar patterns of performance before reaching the top ranking positions.

Competing interests

The author declares that he has no competing interests.

Received: 12 May 2014 Accepted: 28 August 2014

Published: 7 September 2014 


\section{References}

Association of Tennis Professional Web site (2014) Singles ranking database., Retrieved from http://www.atpworldtour.com

Bane MK, Reid M, Morgan S (2014) Has player development in men's tennis really changed? An historical rankings perspective. J Sports Sci 22:1-8

Brouwers J, De Bosscher V, Sotiradou P (2012) An examination of the importance of performances in youth and junior competition as an indicator of later success in tennis. Sports Manage Rev 15:461-475

Cummings P, Koepsell TD (2010) P values vs. estimates of associations with confidence intervals. Arch Pediatr Adolesc Med 164:193-195

Maquirriain J, Cerúndolo A (2005) Age trends in professional tennis players. Med Sci Sports Exerc 41:85

Radicchi $F$ (2011) Who is the best player ever? A complex network analysis of the history of professional tennis. PLoS One 6:e17249

Reid M, Morris C (2011) Ranking benchmarks of top 100 players in men's professional tennis. Eur J Sport Sci 13:350-355

Reid M, Morgan S, Churchill T, Bane MK (2014) Rankings in professional men's tennis: a rich but underutilized source of information. J Sports Sci 32:986-992

Rohm AJ, Chaterjee S, Habibullah M (2004) Strategic measure of competitiveness for ranked data. Manage Decis Econ 25:103-108

Women Tennis Association Web site (2014) Singles ranking database., Retrieved from http://www.wtatennis.com

doi:10.1186/2193-1801-3-504

Cite this article as: Maquirriain: Analysis of tennis champions' career: how did top-ranked players perform the previous years? SpringerPlus $20143: 504$

\section{Submit your manuscript to a SpringerOpen ${ }^{\circ}$ journal and benefit from:}

- Convenient online submission

- Rigorous peer review

- Immediate publication on acceptance

- Open access: articles freely available online

- High visibility within the field

- Retaining the copyright to your article

Submit your next manuscript at $>$ springeropen.com 